First publ. in: Marine Biology 133 (1999), 1, pp. 79-90

E. Braga $\cdot$ R. Zardoya $\cdot$ A. Meyer $\cdot$ J. Yen

\title{
Mitochondrial and nuclear rRNA based copepod phylogeny with emphasis on the Euchaetidae (Calanoida)
}

Received: 9 October 1997 / Accepted: 5 August 1998

\begin{abstract}
Phylogenetic relationships within the copepod family Euchaetidae and between representatives of three copepod orders (Calanoida, Harpacticoida, and Poecilostomatoida) were investigated using partial nucleotide sequences of the mitochondrial $16 \mathrm{~S}$ rRNA and the nuclear 28S rRNA genes. DNA isolation, polymerase chain reaction, cloning, and DNA sequencing techniques were customized for these crustaceans. Our results support the monophyly of each copepod order, but in contrast to traditional morphology-based phylogenies of copepod orders, the Poecilostomatoida are basal to the Calanoida and Harpacticoida on our DNA-based phylogenetic tree. Phylogenetic trees generated by maximum parsimony, neighbor-joining, and maximumlikelihood analyses support the classification of the genera Euchaeta and Paraeuchaeta in the family Euchaetidae; results, however, suggest that Euchaeta acuta Giesbrecht is more closely related to species of the genus Paraeuchaeta than to those of Euchaeta, although limited taxon sampling may be partially responsible for this result. Phylogenetic mapping using the most parsimonious 16S tree suggests that the morphological synapomorphies distinguishing the genus Euchaeta evolved independently twice during the history of the Euchaetidae. Further, phylogenetic mapping suggests that the most recent common ancestor of the Euchaetidae and the Aetideidae was a deep-living, vertically migrating
\end{abstract}

Communicated by J.P. Grassle, New Brunswick

E. Braga $\cdot$ J. Yen $(\bowtie)$

Marine Sciences Research Center,

State University of New York at Stony Brook,

Stony Brook, New York 11794-5000, USA

R. Zardoya

Museo Nacional de Ciencias Naturales,

Jose Gutierrez Abascal, 2,

E-28006 Madrid, Spain

A. Meyer

Department of Biology,

University of Konstanz,

D-78457 Konstanz, Germany copepod, and that a bathypelagic, vertically migrating lifestyle characteristic of Paraeuchaeta is an ancestral trait of the family Euchaetidae which was lost apomorphically by Euchaeta. The application of a molecular clock suggests that the sibling species Euchaeta rimana Bradford and Euchaeta marina (Prestandrea) diverged due to the emergence of the Panamanian land bridge.

\section{Introduction}

Ambiguous morphological relationships and a poor fossil record have so far hindered progress in copepod systematics (e.g. Bradford 1973; Fontaine 1988; Huys and Boxshall 1991; Bucklin et al. 1992, 1995). DNA sequence data provide complementary and informative phylogenetic data for determining evolutionary relationships among morphologically similar species (e.g. Palumbi and Benzie 1991; Bucklin et al. 1992; Knowlton et al. 1993). Yet, until now, only three molecular systematic studies of copepods have been published: Burton and Lee (1994) examined conspecific relationships of several Tigriopus californicus populations using the mitochondrial cytochrome $c$ oxidase subunit I gene and the nuclear histone H1 gene, and Bucklin et al. (1992, 1995) used nucleotide sequences of a mitochondrial 16S rRNA gene fragment to infer interspecific relationships of three Calanus and a Metridia species in one study, and of six Calanus, three Metridia, and a Nannocalanus species in another. Higher taxonomic relationships among copepods have not yet been examined with molecular data.

In the present study we used mitochondrial DNA sequence data to address systematic relationships among copepods, primarily within the family Euchaetidae (Calanoida). The Euchaetidae are found throughout the world's oceans, inhabiting tropical, temperate, and polar waters, and are vertically distributed throughout the epi-, meso-, and bathypelagic zones (Park 1975, 1995). Since its establishment by Sars (1902), systematic relationships within this family have been contentious. The 
generic status of some members of the Euchaetidae has been the center of the debate, and previous comparative morphological studies have supported a single genus versus two or more genera within this family (Brodsky 1950; Bradford et al. 1983; Park 1995 and references therein). Subtle morphological distinctions and a lack of morphological characters that clearly define genera have been the primary obstacles impeding progress in Euchaetidae systematics. For example, Vervoort (1957), among several other authors, opposed dividing the family Euchaetidae into Euchaeta and Paraeuchaeta, declaring that a number of "intermediate" species possess phenotypes found in both genera. He proposed that all euchaetids be merged into a single genus, Euchaeta, and this monogeneric classification was subsequently followed in several systematic studies of the Euchaetidae (e.g. Fontaine 1967, 1988; Park 1975, 1978). A detailed summary of the history of the problematic systematics of this family is provided by Park $(1978,1995)$.

Although Park $(1975,1978)$ previously followed Vervoort's monogeneric classification, he has recently redefined the family Euchaetidae based on morphological characteristics and has recognized two genera, Euchaeta and Paraeuchaeta. Park (1995) has assigned 34 of the 130 known euchaetid species to the genus Euchaeta, and the other species to Paraeuchaeta. He has further subdivided the genus Euchaeta into three species groups (marina, concinna, and acuta) and one separate lineage (Euchaeta spinosa), and the genus Paraeuchaeta into six species groups (norvegica, pavlovskii, malayensis, glacialis, hebes, and antarctica) and three separate lineages (Paraeuchaeta biloba, Paraeuchaeta grandiremis, and Paraeuchaeta bisinuata) (Fig. 1). Interestingly, Park's (1995) revision of the family Euchaetidae corresponds with the ecologically distinct life histories of Euchaeta and Paraeuchaeta. Species in the genus Euchaeta are generally small ( $\sim 2$ to $4 \mathrm{~mm}$ ), shallow-living (surface to $500 \mathrm{~m}$ ), warm water copepods, whereas Paraeuchaeta species are predominantly large $(\sim 7$ to $10 \mathrm{~mm})$, bathypelagic (1000 to $4000 \mathrm{~m})$, vertically migrating, cold water copepods (Brodsky 1950; Bradford 1974; Bradford et al. 1983; Park 1975, 1978, 1994, 1995; Yen 1983; Ferrari and Dojiri 1987; Fontaine 1988; Zmijewska and Yen 1993).

We examined phylogenetic relationships among species in the family. Euchaetidae using partial mitochondrial 16S rRNA nucleotide sequences, primarily to address the question of whether Euchaeta and Paraeuchaeta, as most recently defined by Park (1995), are valid genera. Morphological and ecological traits of the Euchaetidae were mapped on the resultant molecular phylogenetic tree in order to examine their patterns of evolution. Also, in order to provide an initial examination of higher taxonomic relationships among copepods based on molecular data, we investigated the relationship of the Euchaetidae (calanoid superfamily Clausocalanoidea) to representatives of other calanoid superfamilies (Eucalanoidea, Centropagoidea, Megacalanoidea, and Arietelloidea) and copepod orders
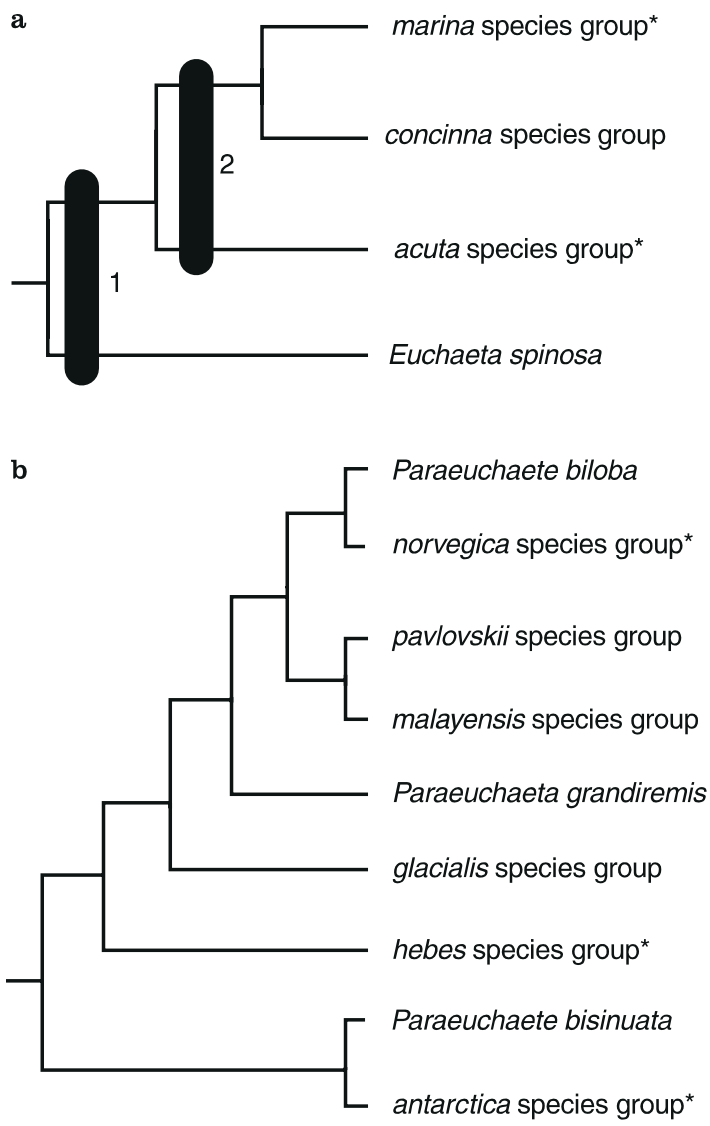

Fig. 1 Morphologically based cladograms of the genera a Euchaeta and b Paraeuchaeta (Park 1995) (* indicates groups from which species were examined in the present study). Bars marked " 1 " and " 2 " represent synapomorphies that distinguish the genus Euchaeta from Paraeuchaeta. Synapomorphy "1" is straight, long, and thick female appendicular caudal setae, and synapomorphy " 2 " is a long, tapering spine on the third exopodal segment of the male fifth left leg. Cladograms were redrawn from Park (1995)

(Harpacticoida and Poecilostomatoida) using the more slowly evolving large ribosomal (28S rRNA) nuclear gene.

\section{Materials and methods}

Species studied

Nineteen copepod species were included in this study, including seven euchaetids (Euchaeta marina, Euchaeta rimana, Euchaeta acuta, Paraeuchaeta norvegica, Paraeuchaeta elongata, Paraeuchaeta similis, and Paraeuchaeta antarctica) (Table 1). A barnacle (Semibalanus balanoides) was added as an outgroup for the $28 \mathrm{~S}$ analysis.

\section{DNA isolation}

Total genomic DNA was isolated from live, frozen $\left(\right.$ at $-70{ }^{\circ} \mathrm{C}$ ), lyophilized, or ethanol-preserved (70 to $95 \%$ ) specimens. Copepods preserved in ethanol were soaked overnight at room temperature in 
Table 1 Classification of study taxa (* marks species included in the $28 \mathrm{~S}$ phylogenetic analysis, $\bullet$ marks species included in the present $16 \mathrm{~S}$ phylogenetic study; with collection localities and year collected)

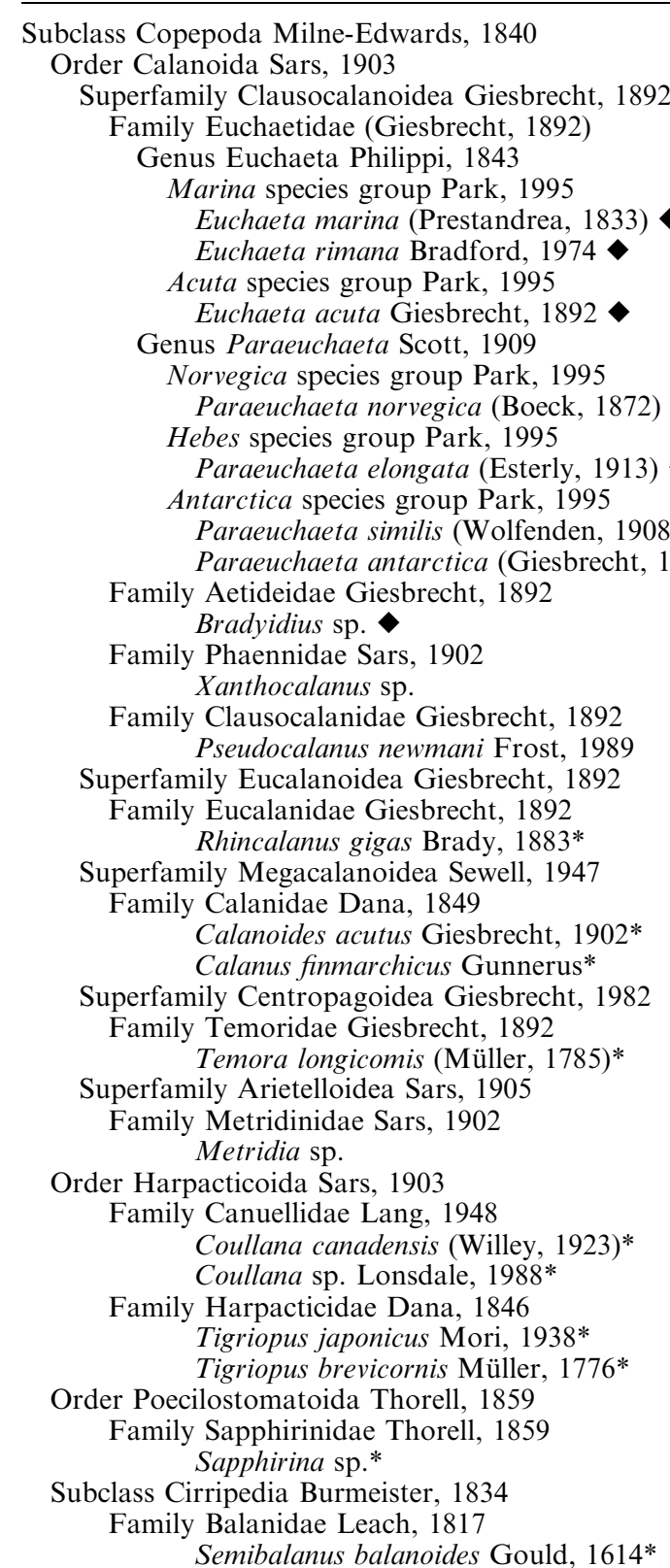

South Florida 1995

Hawaii 1994

Mediterranean Sea, Villefranche 1995

Oslofjord 1995

Dabob Bay 1985

Croker Passage, Antarctica 1989

Croker Passage, Antarctica 1989

Hawaii 1994

Croker Passage, Antarctica 1989

Croker Passage, Antarctica 1989

Gulf of Maine 1992

Stony Brook Harbor 1995

Hawaii 1994

Patuxent River, Lusby, Maryland 1994

St. Sebastian River, Sebastian, Florida 1995

L. Hamana, Japan 1970

Mediterranean Sea, Cullera, Spain 1996

Hawaii 1994

Stony Brook Harbor 1994
$\mathrm{ddH}_{2} \mathrm{O}$ prior to the DNA extraction procedure. One to several copepods (contingent upon their size) in a centrifuge tube were immersed in liquid nitrogen and immediately crushed with a pestle. Genomic DNA was isolated following the method of Towner (1991): after resuspending the pulverized copepod in $1 \mathrm{ml}$ of extraction buffer $(0.14 M \mathrm{NaCl}, 1.5 \mathrm{~m} M \mathrm{Mg}$ acetate, $5 \mathrm{~m} M \mathrm{KCl}, 1 \%$ SDS), DNA was separated from other cell components by the addition of 1 vol of a pre-mixed 25:24:1 phenol/chloroform/isoamyl alcohol solution. Following chilling on ice for $5 \mathrm{~min}$ and centrifugation for $5 \mathrm{~min}$ at $16000 \times g$, the upper aqueous layer was collected and precipitated with 0.1 vol of $3 M$ sodium acetate $(\mathrm{pH}$ 6.8 ) and 2 vol of ethanol $\left(95 \%,-20^{\circ} \mathrm{C}\right)$. Samples were subsequently kept at $-70{ }^{\circ} \mathrm{C}$ for $3 \mathrm{~h}$ (or $-20^{\circ} \mathrm{C}$ overnight), then centrifuged for $10 \mathrm{~min}$ at $16000 \times \mathrm{g}$. The supernatant was discarded, and the resultant DNA pellet was washed with $70 \%$ ethanol, dried, and resuspended in $50 \mu \mathrm{ldd} \mathrm{H}_{2} \mathrm{O}$.
Polymerase chain reaction

Targeted segments of the $16 \mathrm{~S}$ mitochondrial and 28S nuclear rRNA genes were amplified using the polymerase chain reaction (PCR; Saiki et al. 1988). Amplifications were performed in $25 \mu \mathrm{l}$ reactions containing $67 \mathrm{~m} M$ Tris buffer ( $\mathrm{pH} 8.3$ ) (concentration of $\mathrm{MgCl}_{2}$ was optimized for the $16 \mathrm{~S}$ and $28 \mathrm{~S}$ primers, to $2.5 \mathrm{mM}$ and $1.5 \mathrm{mM}$, respectively), 1 to $1000 \mathrm{ng}$ of template DNA, $2.5 \mu M$ of each primer, 0.5 units of AmpliTaq DNA polymerase (Perkin/Elmer-Cetus), and $0.4 \mathrm{~m} M$ of each dNTP. PCR conditions were: $2 \mathrm{~min}$ at $90^{\circ} \mathrm{C}$ (to denature the DNA, and to promote more specific primer annealing), followed by 35 cycles of denaturation at $94{ }^{\circ} \mathrm{C}$ for $60 \mathrm{~s}$, annealing at 48 to $50{ }^{\circ} \mathrm{C}$ for $60 \mathrm{~s}$, and extending at $72{ }^{\circ} \mathrm{C}$ for $60 \mathrm{~s}$. An aliquot $(5 \mu \mathrm{l})$ of each amplification product was electrophoresed on a $1.5 \%$ agarose gel stained with ethidium bromide to confirm that DNA fragments were of the correct length and uncontaminated. 
Primers D9/10 Forward (5'-CGGCGGGAGTAACTATGACTCTCTTAAGGT-3') and D9/10 Reverse (5'-CCGCCCCAGCCAAACTCCCCA-3') (Zardoya et al. 1995) were used to amplify the $28 \mathrm{~S}$ rRNA gene fragment. The $16 \mathrm{~S}$ rRNA gene fragment was amplified with universal primer 16Sar-L (5'CGCCTGTTTATCAAAAACAT-3') (Palumbi et al. 1991) and new internal primer 16S CB (5'-ATTCAACATCGAGGTCACAA-3'). Universal primers 16 Sar-L (5'-CGCCTGTTTATCAAAAACAT$\left.3^{\prime}\right)$ and 16Sbr-H (5'-CCGGTCTGAACTCAGATCACGT-3') (Palumbi et al. 1991) used by Bucklin et al. (1992) to amplify an internal portion of calanoid copepod mitochondrial 16S rRNA were initially used for calanoid copepods in this study but resulted in several products. New internal primers 16S CA (5'-TGTTAAGGTAGCATAGTAAT-3') and 16S CB (5'-ATTCAACATCGAGGTCACAA-3') were designed based on highly conserved regions of the 430-base pair (bp) 16S rRNA gene segment of Calanus copepods sequenced by Bucklin et al. (1992), but successfully amplified only calanoid 16S DNA. It was later discovered that primer $16 \mathrm{~S} \mathrm{CB}$ used in conjunction with the universal primer $16 \mathrm{Sar}-\mathrm{L}$ consistently produced superior PCR products for calanoid copepods as well as other copepod orders (orders Harpacticoida and Poecilostomatoida) and more distantly related crustaceans (e.g. Semibalanus balanoides) which were not included in this 16S phylogenetic analysis.

\section{Cloning and DNA sequencing}

The pGEM-T Vector System (Promega) was used to clone the PCR products. Competent Escherichia coli cells were cultivated and transformed with recombinant plasmids following Sambrook et al. (1989). Positive clones were selected from LB plates coated with IPTG and X-gal and containing $50 \mu \mathrm{g} \mathrm{ml}^{-1}$ ampicillin, and plasmid DNA was isolated from the positive clones using the Wizard Minipreps DNA Purification System (Promega). The isolated plasmids were ethanol-precipitated in the presence of $300 \mathrm{mM}$ sodium acetate, washed with $70 \%$ ethanol, dried, and resuspended in $30 \mu \mathrm{ldd} \mathrm{H}_{2} \mathrm{O}$

The FS Taq Dye Deoxy Terminator Cycle Sequencing Kit (Applied Biosystems) was used to cycle sequence an aliquot (1 to $3.5 \mu \mathrm{l}$ ) of the prepared plasmid solution on an Applied Biosystems 373 Stretch DNA Sequencer. Both pUC/M13 Universal (-40) and Reverse-sequencing primers were used in the cycle-sequencing reactions to sequence both DNA strands in their entirety.

\section{Sequence alignment and phylogenetic analysis}

Multiple-sequence alignments were performed using CLUSTAL W (Thompson et al. 1994), followed by visual refinement of the sequence alignment where unambiguous manual adjustments were necessary (these areas were always associated with gaps in a sequence). Default settings for gap weight and gap length penalties were used to maximize alignment of homologous character sites. Gaps resulting from the alignment were treated as missing data.

The aligned sequences were subjected to three phylogenetic methods using PAUP* Version 4.0d54 (Swofford 1997): maximum parsimony (MP) (Fitch 1971), neighbor-joining (NJ) (Saitou and Nei 1987), and maximum likelihood (ML) (Felsenstein 1981). The exact method used in the MP analysis was contingent upon the number of taxa examined: branch-and-bound searches were used for 11 to 13 taxa, and exhaustive searches for $\leq 10$ taxa. In the ML analysis, the Hasegawa-Kishino-Yano 85 model (Hasegawa et al. 1985) was used; this model takes into account unequal base composition and different rates of evolution for transitions (TIs: $\mathrm{C} \leftrightarrow \mathrm{T}$ and $\mathrm{A} \leftrightarrow \mathrm{G}$ ) and transversions (TVs: all other substitutions). Kimura two-parameter distance matrices were used in the $\mathrm{NJ}$ analysis, to account for multiple hits as well as the proportion of TIs to TVs between sequence pairs (Kimura 1980). Robustness of the inferred MP and NJ trees was tested with bootstrap analyses (Felsenstein 1985) (PAUP*, 100 replications).
The statistical confidence of alternative trees with respect to the resultant most parsimonious MP tree(s) and the best ML tree was evaluated with the methods of Templeton (1983) and Kishino and Hasegawa (1989), respectively, as implemented in PAUP*. The method of Templeton (1983) evaluates the standard deviation of the difference in tree length between the shortest MP tree(s) and the alternative tree, and the formula of Kishino and Hasegawa (1989) is used to calculate the standard deviation of the difference in loglikelihoods between the resulting best ML tree and the competing tree. Alternative trees can be statistically rejected when the difference in the number of steps or log-likelihoods is found to be more than 1.96 times the standard deviation (Felsenstein 1989).

Lastly, MacClade (Version 3.06; Maddison and Maddison 1992), which is based on the parsimony criterion, was implemented to map morphological and ecological traits of the family Euchaetidae over the shortest MP phylogenetic tree inferred from the $16 \mathrm{~S}$ data. Traits mapped included the two morphological synapomorphies that distinguish Euchaeta from Paraeuchaeta (the female appendicular caudal setae and male left fifth leg), and ecological traits of Euchaeta and Paraeuchaeta (vertical distribution and associated vertical migration patterns).

\section{Outgroup selection and weighting strategies}

A representative (Bradyidius sp.) of the family Aetideidae, the presumed sister family to the Euchaetidae (Park 1995), was included in the $16 \mathrm{~S}$ analysis to serve as the outgroup for examining evolutionary relationships among euchaetids. Park (1995) also used the family Aetideidae as the outgroup to polarize morphological character states of the Euchaetidae. The sensitivity of the $16 \mathrm{~S}$ results to variation in outgroup was evaluated with representatives from two families [Xanthocalanus sp. (family Phaennidae) and Pseudocalanus newmani (family Clausocalanidae)] belonging to the same calanoid superfamily to which the Euchaetidae and Aetideidae belong (superfamily Clausocalanoidea), using MP bootstrap analyses. The family Phaennidae is considered to be the second most closely related family to the Euchaetidae (Fontaine 1988).

Semibalanus balanoides (subclass Cirripedia) served as the outgroup to the copepod ingroup in the phylogenetically more inclusive $28 \mathrm{~S}$ analysis, and Drosophila melanogaster was included in the $28 \mathrm{~S}$ sequence alignment to test the sensitivity of the results to variation in outgroup. Molecular data have supported a sister group relationship between the subclass Cirripedia and the subclass Copepoda (Abele et al. 1992).

The sensitivity of the phylogenetic results to various weighting strategies was tested. The following weights were applied a priori in the phylogenetic analyses to both the $16 \mathrm{~S}$ and $28 \mathrm{~S}$ data: $\mathrm{TI}=1 \mathrm{TV}$, 2TV, 3TV, 9TV, and TV only. The sensitivity of the results to these varied weights was tested with MP bootstrap analyses. Alternatively, weights were assigned a posteriori by the successive approximations approach (Farris 1969). In this approach, the most parsimonious tree is first obtained by PAUP* using a branch-andbound or exhaustive search and equal weights. Characters are then reweighted iteratively based on their rescaled consistency index until an unchanging topology is obtained.

\section{Results}

\section{Sequence analysis}

Primers 16Sar-L and 16S CB consistently amplified a 16S gene fragment of 356 to $387 \mathrm{bp}$, but since sequences from several euchaetid species had been previously obtained with primers $16 \mathrm{~S} \mathrm{CA}$ and $16 \mathrm{~S} \mathrm{CB}$, the additional base pairs $(\sim 70)$ using 16Sar-L and 16S CB were excluded from this analysis. With the exclusion of the extra base pairs, the lengths of the copepod 16S sequences ranged between 284 and $313 \mathrm{bp}$. Primers D9/10-For- 
ward and D9/10-Reverse consistently amplified a $28 \mathrm{~S}$ gene fragment of 327 to $350 \mathrm{bp}$ for all 21 study taxa. The $28 \mathrm{~S}$ sequence of Semibalanus balanoides was $350 \mathrm{bp}$ in length, while the $28 \mathrm{~S}$ sequences of the copepods ranged between 327 and $341 \mathrm{bp}$. A previously published $28 \mathrm{~S}$ Drosophila melanoganster sequence of the same region was included in the sequence alignment (Tautz et al. 1988).

The aligned $16 \mathrm{~S}$ and $28 \mathrm{~S}$ sequences are presented in Figs. 2 and 3, respectively. Among the aligned 16S DNA sequences, ambiguously aligned nucleotides were always associated with large alignment gaps and were excluded from the calculations of pairwise distances and from the phylogenetic analyses (Fig. 2). All sites were included in the $28 \mathrm{~S}$ phylogenetic analysis because all positions could be aligned unambiguously.

Base composition was assessed, and was similar among taxa in each data set. As in other invertebrate mtDNA, the $16 \mathrm{~S}$ gene fragment exhibited a strong bias towards A's and T's (mean percentage A, C, G, T = 40, 9,13 , and $38 \%$, respectively) (Palumbi and Benzie 1991; Bucklin et al. 1992; Funk et al. 1995). Conversely, the four nucleotides were distributed almost equally in the $28 \mathrm{~S}$ gene fragments of the study taxa (mean percentage of A, C, G, T $=24,24,27$, and $24 \%$, respectively).

\section{S phylogenetic analysis of copepod orders}

To provide an initial examination of higher taxonomic relationships between copepods, and to place the family Euchaetidae into a larger phylogenetic framework, evolutionary relationships between representatives of three copepod orders (Calanoida, Harpacticoida, and Poecilostomatoida) and five calanoid superfamilies (Clausocalanoidea, Eucalanoidea, Centropagoidea, Megacalanoidea, and Arietelloidea) were inferred from aligned nucleotide sequences of the D9/D10 region of the 28S rRNA gene. A single most parsimonious tree was found using a branch-and-bound MP search (249 steps, CI $=0.8233$, TI and TV weighted equally, 83 parsimony-informative sites) with Semibalanus balanoides as the outgroup (Fig. 4). Internal nodes of this tree were well-supported by bootstrap values (Fig. 4). Further, the same topology was recovered regardless of the type of phylogenetic analysis performed, including NJ, ML (ln-likelihood $=-1658.43$ ), variation in outgroup (outgroup modifications included: Drosophila melanoganster and $S$. balanoides together, D. melanoganster alone, Sapphirina sp. alone, and the four harpacticoids together), successive approximations weighting, and upweighting of TVs (though with less resolution between calanoid superfamilies as TVs were upweighted more than two times over TIs or when TIs were excluded, suggesting a loss of valuable phylogenetic information from TIs had occurred).

The monophyly of each copepod order was strongly supported by these results. As in Huys and Boxshall's (1991) phylogeny of copepod orders (Fig. 5a), the Har- pacticoida grouped more closely to the Calanoida than did the Poecilostomatoida. However, in the morphologybased tree the Calanoida are basal to the Harpacticoida and Poecilostomatoida, whereas in the DNA-based tree (Fig. 4) the Poecilostomatoida are basal to the Harpacticoida and Calanoida; both Templeton (1983) and Kishino-Hasegawa (1989) tests statistically rejected the morphology-based hypothesis with respect to our recovered molecular phylogeny (ln-likelihood = $-1698.18, \Delta \ln L=33.59, \mathrm{SD}=10.33 ; 314$ steps, $\Delta$ steps $=23, \mathrm{SD}=5.20$ ).

Moreover, evolutionary relationships between calanoid superfamilies inferred from 28S rRNA sequence data agree with the traditional morphology-based phylogeny (Fig. 5b; Park 1986), except for the positions of Arietelloidea (formerly Augaptiloidea) and Centropagoidea, which are reversed. In agreement with the traditional phylogenetic view, the Clausocalanoidea (represented by Paraeuchaeta antarctica) and Eucalanoidea (represented by Rhincalanus gigas) are relatively recent calanoid superfamilies. Templeton (1983) and Kishino-Hasegawa (1989) tests were implemented to establish whether the traditional phylogenetic view in which the superfamily Arietelloidea is placed basally to the Centropagoidea (Fig. 5b) could be statistically rejected with respect to the molecular phylogeny in which the superfamily Centropagoidea is placed basally to the Arietelloidea (Fig. 4). The traditional phylogenetic hypothesis could be statistically ruled out based on the results of the Templeton (1983) test (260 steps, $\Delta$ steps $=4, \mathrm{SD}=1.99)$, but could not be ruled out based on the results of the Kishino-Hasegawa (1989) test (lnlikelihood $=-1660.69, \Delta \ln L=8.11, \mathrm{SD}=13.26$ ).

\section{S phylogenetic analysis of the Euchaetidae}

Phylogenetic relationships within the copepod family Euchaetidae were examined using a partial nucleotide sequence of the mitochondrial 16S rRNA gene. A single most parsimonious tree was found with an exhaustive search (263 steps, CI $=0.77$, TIs and TVs weighted equally, 91 parsimony-informative sites) and Bradyidius sp. as the outgroup (Fig. 6). In this shortest MP tree, euchaetid species group, as expected, based on morphological and ecological information, with the exception of Euchaeta acuta which grouped with $\mathrm{Pa}$ raeuchaeta norvegica and Paraeuchaeta elongata within a clade comprising the four Paraeuchaeta species. The same topology was recovered in NJ and ML analyses (ln-likelihood $=1430.54)$. Bootstrap analyses using both MP and NJ methods highly supported all nodes of this tree, with the exception of the node grouping $E$. acuta with $P$. norvegica and $P$. elongata (bootstrap value $=60$ and $53 \%$, respectively) (Fig. 6). The next shortest MP tree was three steps longer, and placed $E$. acuta as sister taxon to the clade of $P$. elongata, P. norvegica, Paraeuchaeta similis, and Paraeuchaeta antarctica. 


E.marina
E.rimana
E.acuta
P.norvegica
P.elongata
P.similis
P.antarctica
Bradyidius sp.
Xanthocalanus sp.
P.newmani
R.gigas
C.acutas

E.marina
E.rimana
E.acuta
P.norvegica
P.elongata
P.similis
P.antarctica
Bradyidius sp.
Xanthocalanus sp.
P.newmani
R.gigas
C.acutas

TAGTTCCCTAATTAGGAATAGAATGAAGAAGACATCATATTATTTTTCTCTGAAATTTTATTTCAAATTTTTATTTTTAGTGAAAATACTAAAATTATGTATTTAGACAAAA

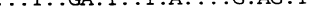

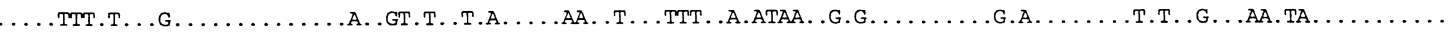

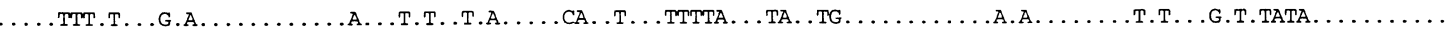

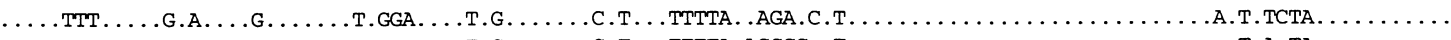

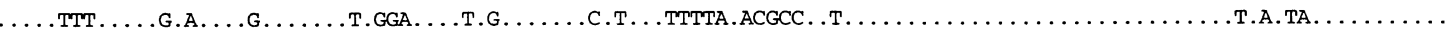

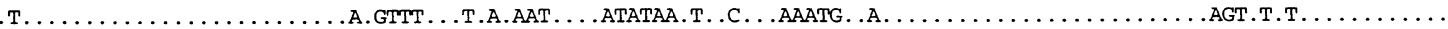

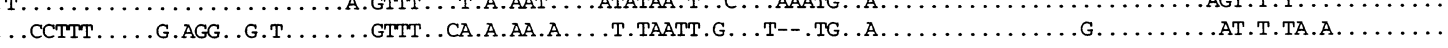

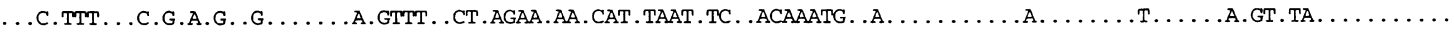

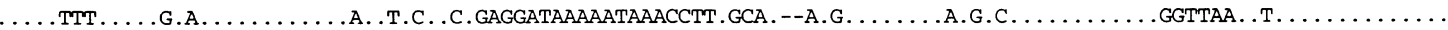

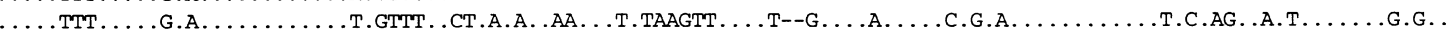

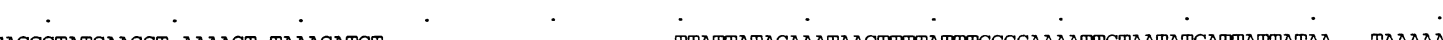

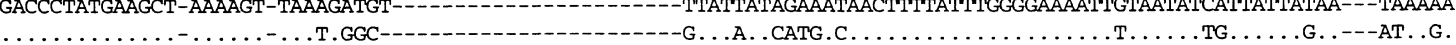
. . . . . . . . . . . . . T.GA.A. .GTA. .AATTATC-_-_-

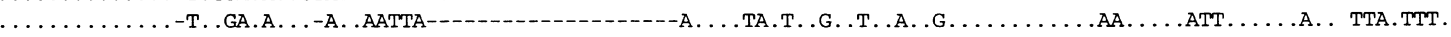
$\ldots \ldots \ldots \ldots \ldots$. . . . АСАСТ. TAG. TATTA-_. $\ldots \ldots \ldots \ldots \ldots$. . . ACACT. TAG. TACTA-_._. ................ T.T. T.G.АTA--

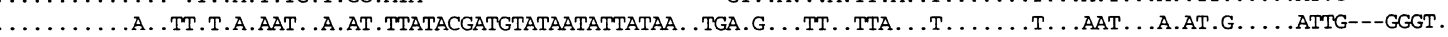

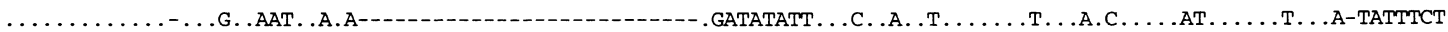
$\ldots \ldots \ldots \ldots$. GCT.GA.AAT. . A. . AATTATA--........

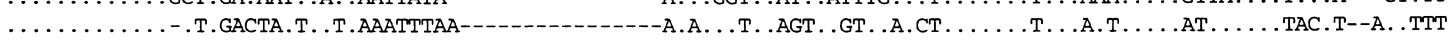

\section{8}

E.marina GAATTAAGTATCCTCT---TTGAATTATGAATAAGCTCCTCTAGGGATAACAGCATAATGATTATTAAAGTCCTAATTGAAATGATC

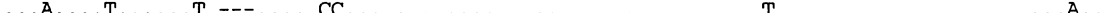

E.acuta $\quad$ А.TAA. .A. . .

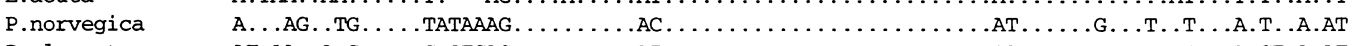

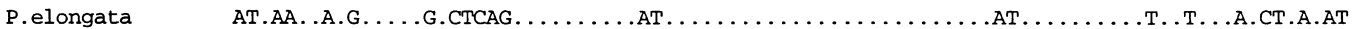

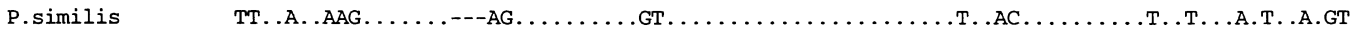

P.antarctica $\quad$ TT..A. AAG......-G. .

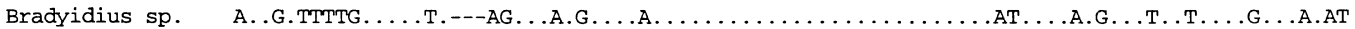

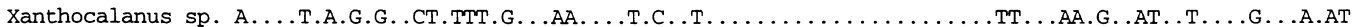

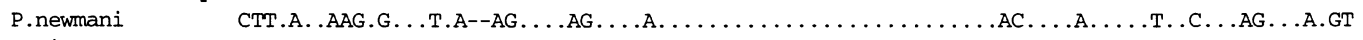

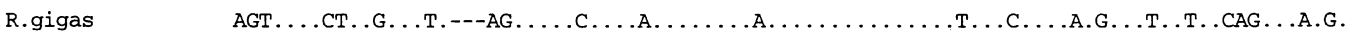

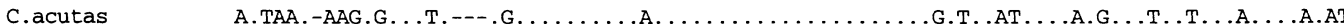

Fig. 2 Alignment of 16S rRNA gene sequences (', same base as uppermost sequence; -, alignment gap). Sites excluded from phylogenetic analysis were: $63-64,130,150-168,222-227$, and 247-249

A tree topology identical to the shortest MP tree was recovered with successive approximations weighting and upweighting TVs two and three times over TIs. When TVs were weighted nine times more than TIs, Euchaeta acuta was placed as in the second shortest MP tree but with only moderate bootstrap support $(54 \%)$. When TIs were excluded, the position of E. acuta was unresolved (bootstrap value $<50 \%$ ), indicating that phylogenetic information was contained in the transitions. Further, the ingroup topology of the best MP tree was robust to different outgroups, with one exception. The same topology as the shortest MP tree (Fig. 6) was recovered with MP bootstrap analyses when the outgroup was Bradyidius sp. and Xanthocalanus sp. together, Xanthocalanus sp. alone, and Bradyidius sp., Xanthocalanus sp., and Pseudocalanus newmani together, though bootstrap values were lower for some nodes, indicating that the mitochondrial 16S DNA fragment does not resolve these distantly related groups. When the outgroup was $P$. newmani alone, however, E. acuta was grouped with Euchaeta marina and Euchaeta rimana with a 77\% MP bootstrap value. The same topology was recovered when this result was further investigated with a NJ analysis, though the node grouping E. acuta with E. marina and E. rimana received a lower NJ bootstrap value $(67 \%)$.
The majority of the phylogenetic analyses favored the most parsimonious tree (Fig. 6). Templeton (1983) and Kishino-Hasegawa (1989) tests, which determine whether alternative trees can be statistically rejected with respect to the best MP and ML trees, showed that neither of the two alternative trees [i.e. Euchaeta acuta as the sister group to the four Paraeuchaeta species (lnlikelihood $=-1431.50, \Delta \ln L=0.97, \mathrm{SD}=4.18 ; 266$ steps, $\Delta$ steps $=3, \mathrm{SD}=3$ ) or E. acuta as the sister group of Euchaeta rimana and Euchaeta marina (nlikelihood $=1437.83, \Delta \ln L=7.29, \mathrm{SD}=7.52 ; 269$ steps, $\Delta$ steps $=6, \mathrm{SD}=5.29)]$ could be ruled out.

Phylogenetic mapping of morphological and ecological traits

Morphological and ecological traits of the family Euchaetidae were mapped onto the most parsimonious 16S tree (i.e. Fig. 6). First, each of the two synapomorphies distinguishing species of the genus Euchaeta was treated as a two-state character (character state present or not present) and mapped (Fig. 7, a and

Fig. 3 Alignment of sequences of 28S D9/D10 region (;, same base as uppermost sequence; -, alignment gap) 
E. marina

E.rimana

E.acuta

P.norvegica

P. elongata

P. similis

P.antarctica

Bradyidius sp.

Xanthocalanus sp.

P.newmani

R.gigas

C. finmarchicus

C. acutus

T. longicornis

Metridia sp.

C. canadensis

Coullana sp.

T. japonicus

T.brevicornis

Sapphirina sp.

S.balanoides

D. melanoganster

E. marina

E.rimana

E. acuta

P.norvegica

P.elongata

P. similis

P. antarctica

Bradyidius sp.

Xanthocalanus sp.

P. newmani

R.gigas

C. finmarchicus

C. acutus

T. longicornis

Metridia sp.

C. canadensis

Coullana sp.

T.japonicus

T.brevicornis

Sapphirina sp.

s.balanoides

D.melanoganster

E.marina

E.rimana

E. acuta

P.norvegica

P.elongata

P.similis

P. antarctica

Bradyidius sp.

Xanthocalanus sp.

P.newmani

R.gigas

C. finmarchicus

c. acutus

T.longicornis

Metridia sp.

C. canadensis

Coullana sp.

T.japonicus

T.brevicornis

Sapphirina sp.

S.balanoides

D.melanoganster

E.marina

E.rimana

E.acuta

P.norvegica

P.elongata

P. elongat

P.antarctica

Bradyidius sp.

Xanthocalanus sp.

P. newmani

R.gigas

C. finmarchicus

C.acutus

T. longicornis

Metridia sp.

C. canadensis

Coullana sp.

T.japonicus

T.brevicornis

Sapphirina sp

S.balanoides

D.melanoganster

AGCCAAATGCCTCGTCATCTAATTAGTGACGCGCATGAATGGATTAACGAGATTCCCACTGTCCCTATCTACTATCTAGCGAAACCGCAGCCAAGGGAACGGACTTGGGAGGATCAGCGGGGAAA

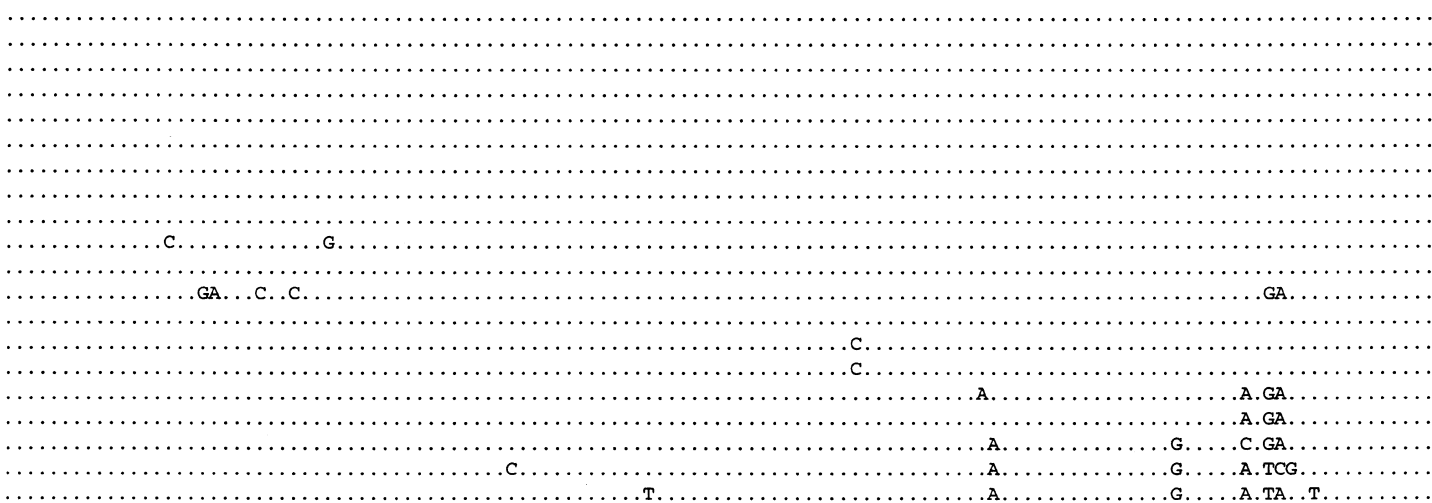

GAAGACCCTGTTGAGCTTGACTCTAGTCTCCTTTTGTAGAGGAGCATTTCTGGCGTAGAATAGGGAGGAGGCTTCGGCCGA CAGTGAAATACTCCTACGGAAATCGCTCCTC

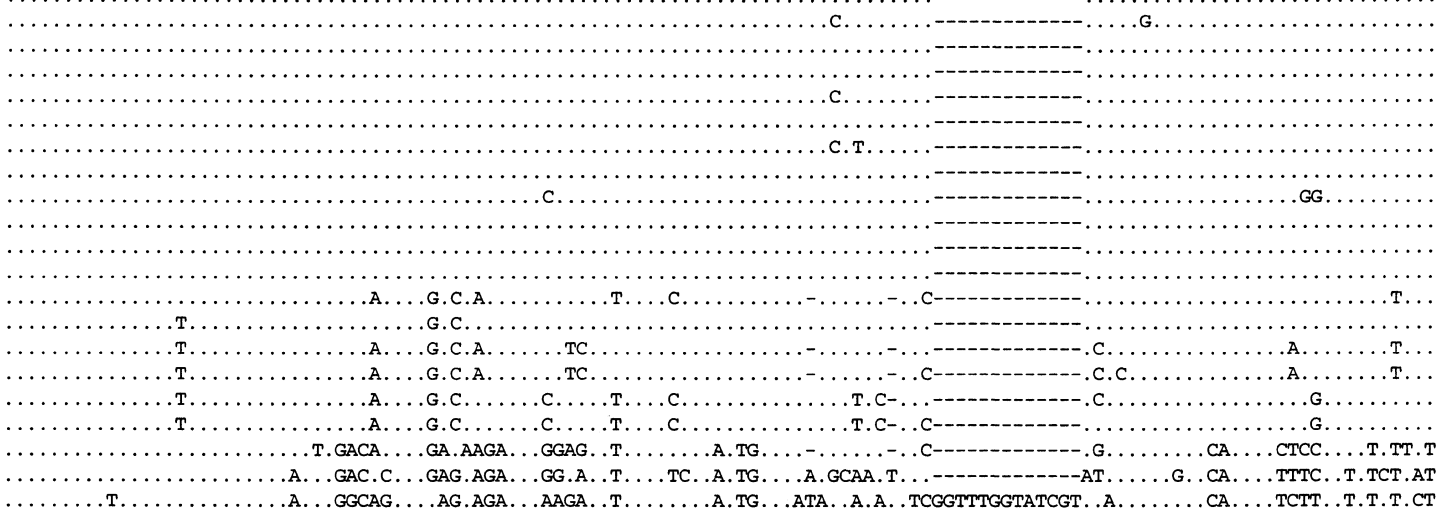

TGCTTACTCGGTTAGGCG-----AAGTTAGGA-CCTTCGGGGC--CTATTTCTCGAATCAAACGGGTCGGCTCTGCCT--GCCC-1.

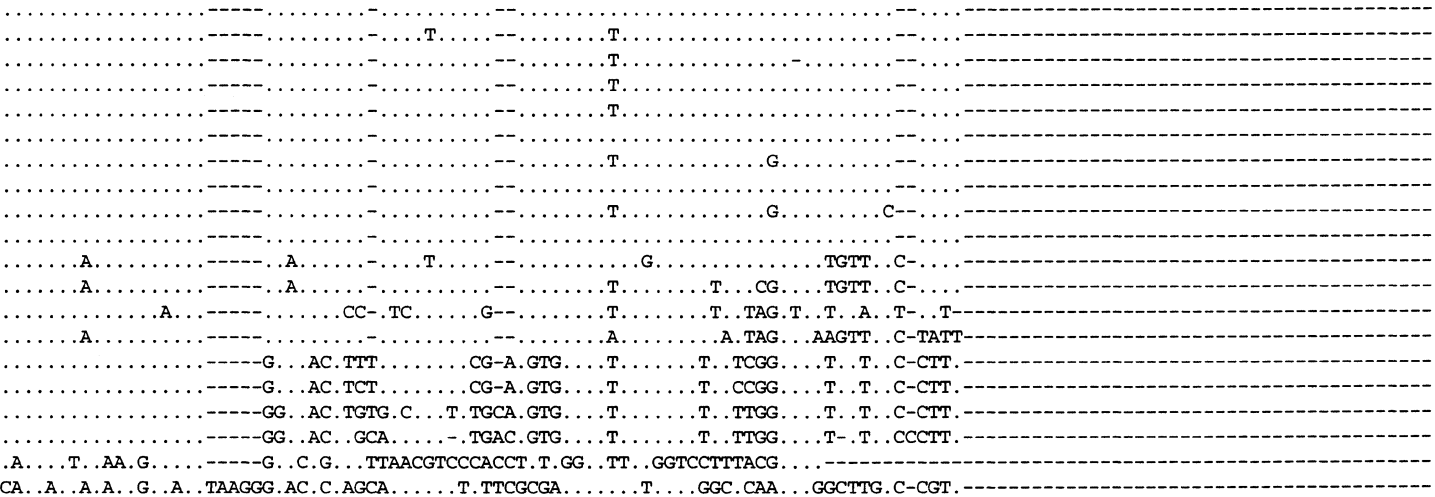

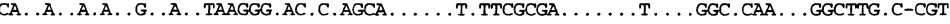

.A. ..... T. A. . AAT. GAACGTGTA. CATTT . . AGCCATTATACGGA. A. ATTTATT. TATCT . AT. G. A. TGGGT-TTTGATGCAAGCTTCTTGATCAAAGTATCCGAGTTTGTTATATAA

484

GTGATTCGCTCCGAG-GACATTGTGAGG

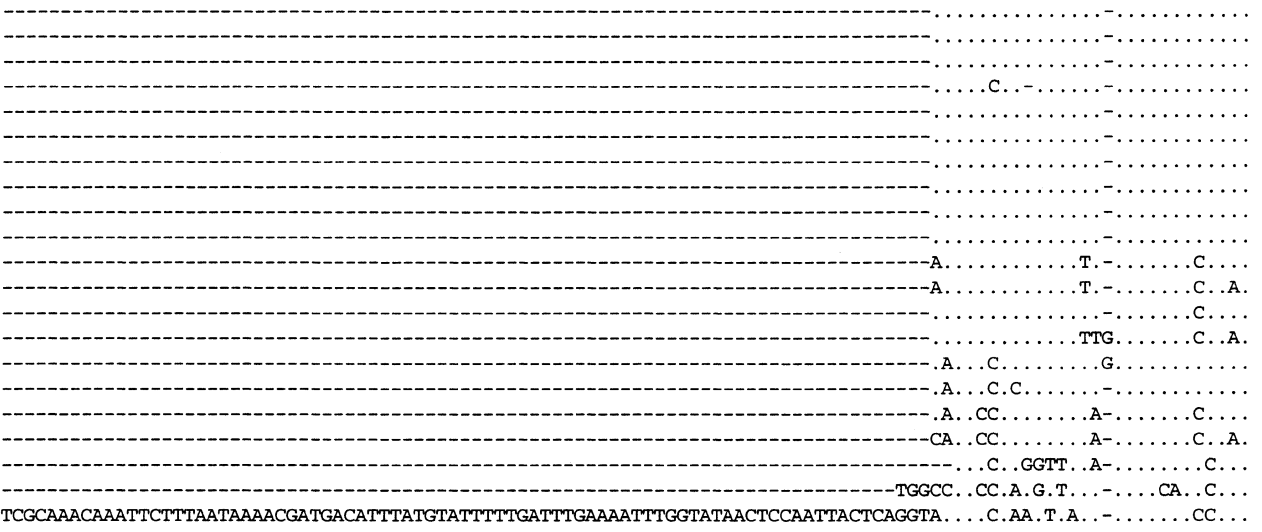


Fig. 4 The most parsimonious tree inferred from the $28 \mathrm{~S}$ data using a branch-and-bound search, with $S$. balanoides as the outgroup (249 steps, all characters weighted equally, $\mathrm{CI}=0.82, \mathrm{RI}=0.76$ ). The monophyly of each copepod order is strongly supported [i.e. node "A" (grouping order Calanoida), node "B", (grouping order Harpacticoida), and node " $\mathrm{C}$ " (separating other copepods from order Poecilostomatoida)], as is the node placing $T$. longicornis basally to the representatives of the other four calanoid superfamilies ("D")

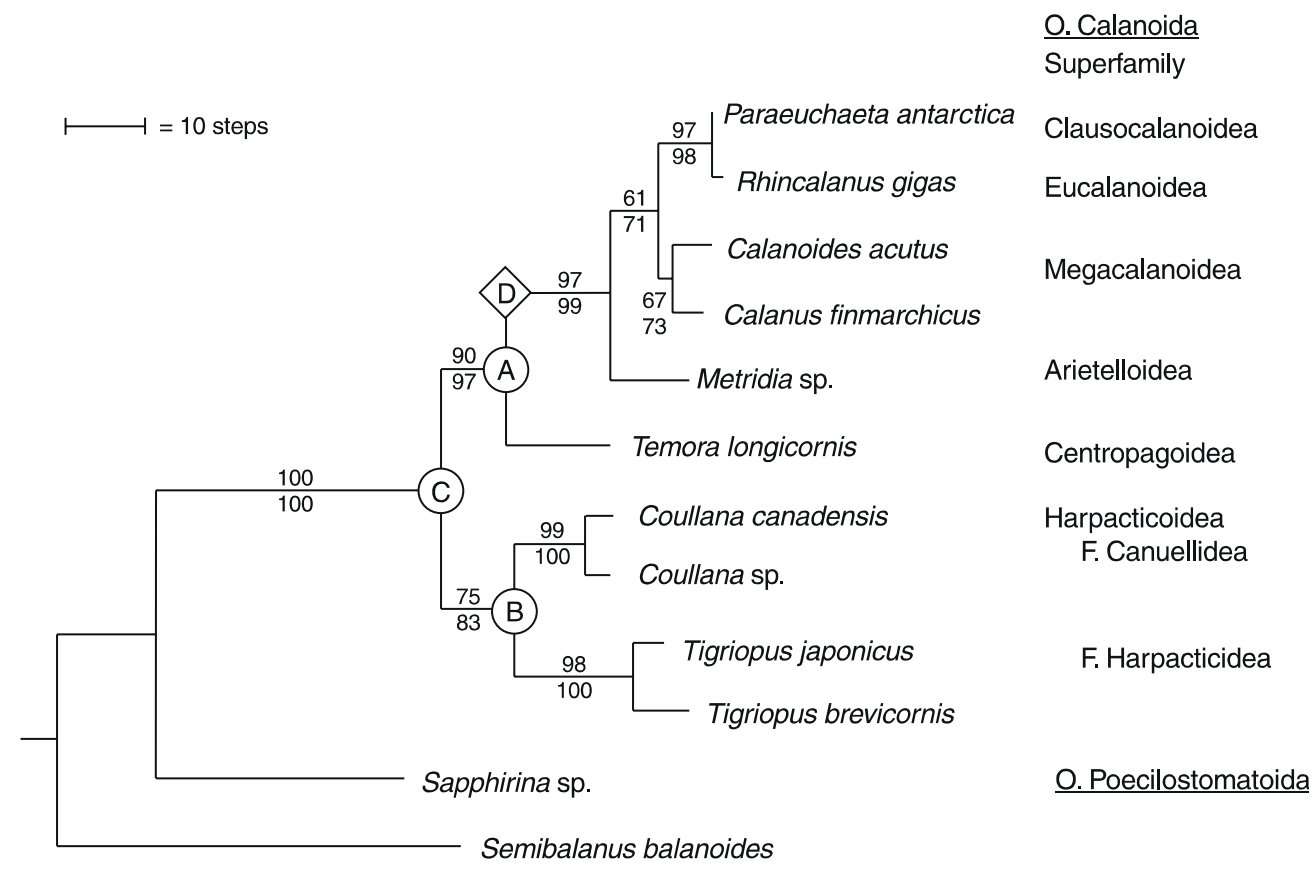

b). According to these character state reconstructions, straight female appendicular caudal setae which are thicker and longer than the distal marginal caudal setae, and a male fifth leg on which the third exopodal segment tapers into a long spine, each evolved independently twice.

We also mapped vertical migration behavior onto the molecular cladogram. Vertical distribution and associated vertical migration patterns were treated as a twostate character (deep-living, extensive vertical migrator or not deep-living and not an extensive vertical migrator) and mapped onto the most parsimonious $16 \mathrm{~S}$ tree (Fig. 7, c). Figure 7(c) shows that a deep-living, vertically migrating lifestyle typical of Paraeuchaeta species was lost twice independently within this family.

The latitudinal distribution of the euchaetids was overlaid on the shortest $16 \mathrm{~S}$ tree recovered (Fig. 8). With the exception of Euchaeta acuta, the inferred phylogenetic relationships of the euchaetids in Fig. 6 are consistent with their latitudinal distribution: Paraeuchaeta antarctica and Paraeuchaeta similis are both antarctic species and are grouped together, Paraeuchaeta norvegica and Paraeuchaeta elongata pair and are both subarctic species, and the two temperate species Euchaeta rimana and Euchaeta marina are identified as sister species. While the antarctic species do co-exist in the same ocean, both the temperate and subarctic species inhabit different ocean basins: E. rimana and $P$. elongata reside in the Pacific, while E. marina and P. norvegica are found in the Atlantic. According to the inferred $16 \mathrm{~S}$ tree, the most parsimonious explanation for the actual distribution pattern of the Euchaetidae species is that their common ancestor is likely to have lived in temperate waters. Two independent migrations to subarctic and antarctic waters would have resulted in the $P$. norvegica/P. elongata and the $P$. similis $/ P$. antarctica clades and distribution patterns, respectively (Fig. 8). Euchaeta acuta, E. marina, and $E$. rimana remained in temperate waters.

Molecular clock

In our final analysis, we investigated the estimated time of divergence for the sister taxa Euchaeta marina and Euchaeta rimana using a molecular clock approach. As expected, our 16S phylogenetic analysis supported the morphology-based sibling species relationship between E. marina and E. rimana (see Fig. 6), which are distinguished by slight differences in the structure of the male left fifth leg and the female genital somite (Park 1995). Following Bermingham and Lessios (1993), who showed that mitochondrial DNA provides a useful molecular clock for studying recent speciation events, we assumed that mitochondrial DNA evolves at a rate of 1.6 to $2.1 \%$ per million years. Based on this molecular clock rate, E. marina and E. rimana diverged from a common ancestor 2.6 to 3.4 million years ago.

\section{Discussion}

28S phylogenetic analysis of copepod orders

An analysis of higher taxonomic relationships between three copepod orders (Calanoida, Harpacticoida, and Poecilostomatoida) and five calanoid superfamilies (Clausocalanoidea, Eucalanoidea, Centropagoidea, 

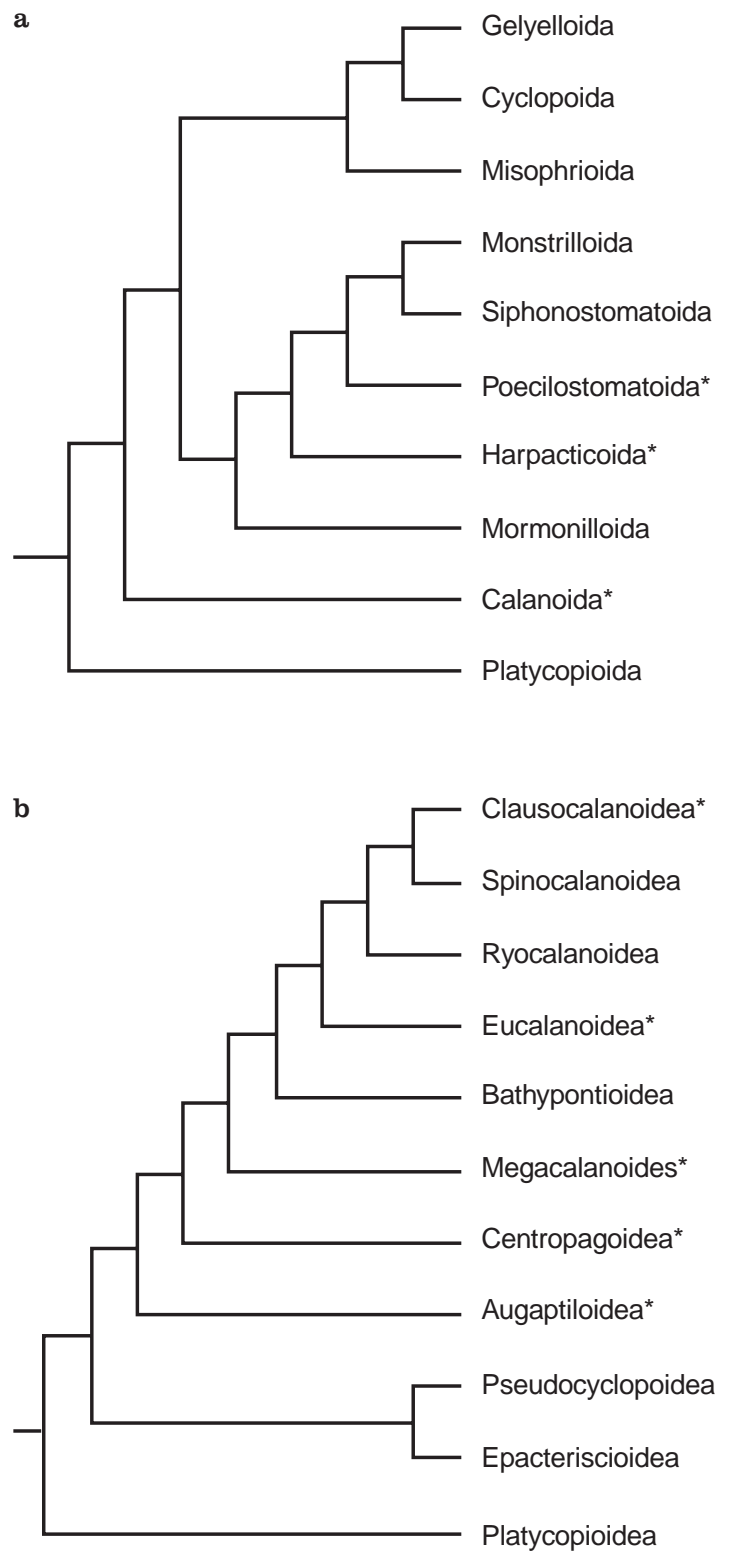

Fig. 5 Morphologically based phylogenies of a copepod orders, redrawn from Huys and Boxshall (1991), and b calanoid superfamilies, redrawn from Park (1986). Note that Augaptiloidea Sars, 1905 has been replaced by Arietelloidea Sars, 1902 on the grounds of priority (Andronov 1991). All families previously included in Augaptiloidea now belong to Arietelloidea (* indicates groups from which taxa were examined in this study)

Megacalanoidea, and Arietelloidea) using aligned nucleotide sequences of the D9/D10 region of the $28 \mathrm{~S}$ rRNA gene generated a single most parsimonious tree (Fig. 4). In this phylogenetic tree, the monophyly of each copepod order is strongly supported, and, as in Huys and Boxshall's (1991) morphology-based phylogeny of copepod orders (Fig. 5a), the Harpacticoida group more closely to the Calanoida than do the Poecilostomatoida. Moreover, evolutionary relationships between calanoid superfamilies inferred from $28 \mathrm{~S}$ rRNA sequence data mostly agree with the traditional morphology-based

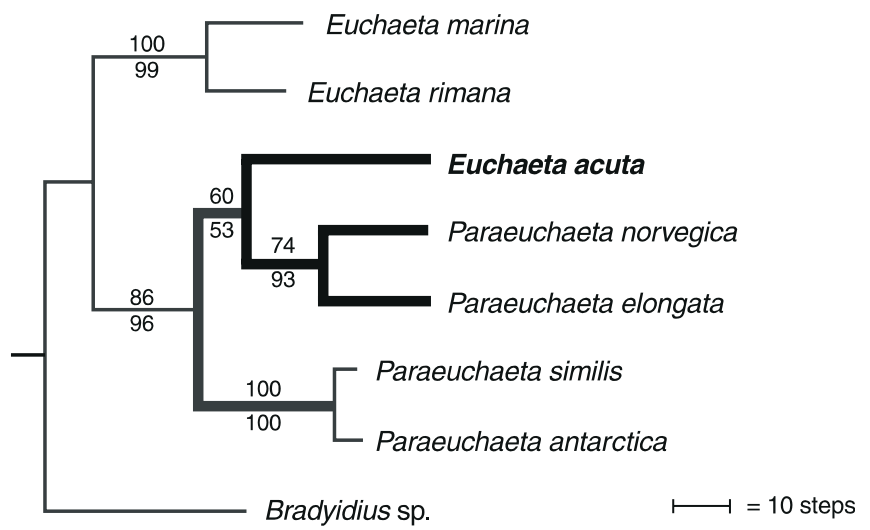

Fig. 6 The most parsimonious tree inferred from the 16S sequence data using an exhaustive search, with Bradyidius sp. as the outgroup (263 steps, all characters weighted equally, $\mathrm{CI}=0.77, \mathrm{RI}=0.60$ ). MP bootstrap values are shown above $\mathrm{NJ}$ bootstrap values

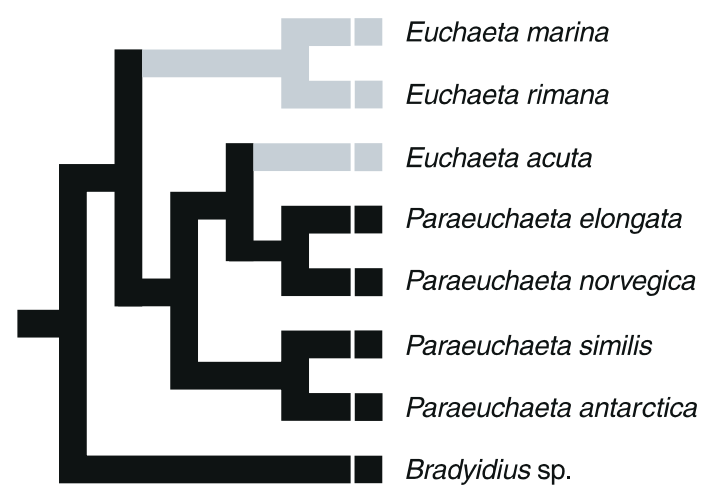

(a) appendicular caudal setae long and straight, (b) distal expodal segment of male left fifth leg tapers into a long spine, (c) shallow-living, does not vertically migrate

(a) appendicular caudal setae long and straight, (b) distal expodal segment of male left fifth leg does not taper into a long spine, (c) shallow-living vertical migrator

Fig. 7 Evolutionary pathways of change of (a) the female appendicular caudal setae in euchaetids, (b) the third exopodal segment of the male fifth leg in euchaetids, and (c) vertical migration behavior of euchaetids, based on the most parsimonious $16 \mathrm{~S}$ tree

phylogeny (Fig. 5b; Park 1986). In agreement with the traditional phylogenetic view, the Clausocalanoidea (represented by Paraeuchaeta antarctica) and Eucalanoidea (represented by Rhincalanus gigas) are relatively recent calanoid superfamilies. Sequence variation between these two superfamilies was low, between 0 and $1.8 \%$, indicating that insufficient time has elapsed since their divergence for numerous mutations to accumulate in this $28 \mathrm{~S}$ gene fragment.

There are some discrepancies between our DNAbased trees and traditional morphology-based trees of copepod orders and calanoid superfamilies. In our molecular tree the Poecilostomatoida are basal to the Harpacticoida and Calanoida (Fig. 4), whereas in Huys 

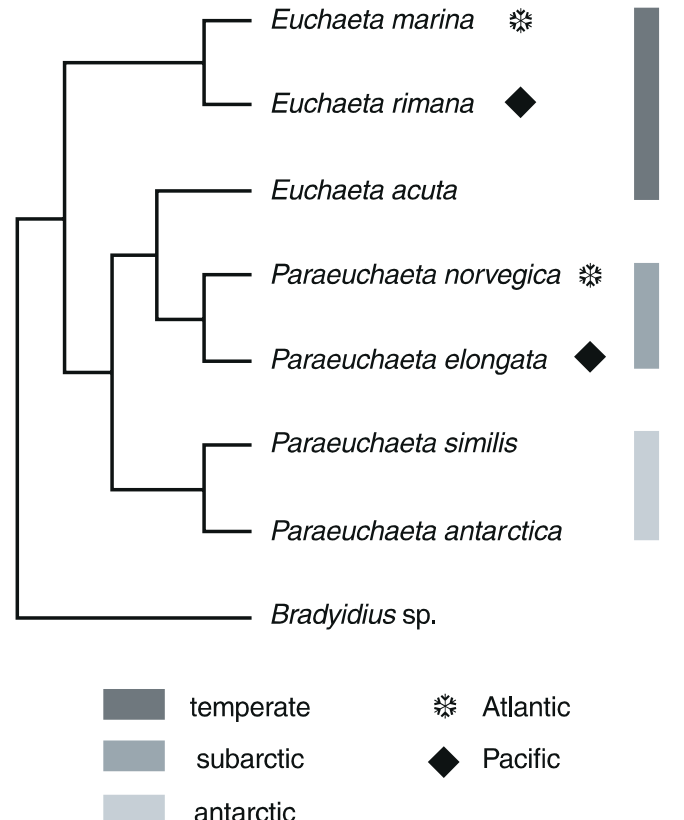

Fig. 8 Latitudinal distribution of the Euchaetidae overlaid on the most parsimonious $16 \mathrm{~S}$ tree

and Boxshall's (1991) morphology-based tree the Calanoida are basal to the Harpacticoida and Poecilostomatoida (Fig. 5a). Templeton (1983) and KishinoHasegawa (1989) tests strongly supported this result; both tests statistically rejected the morphology-based hypothesis with respect to our recovered molecular phylogeny. Also, the positions of the calanoid superfamilies Arietelloidea and Centropagoidea in Fig. 4 are reversed in comparison to their placement in Park's (1986) morphology-based tree of calanoid superfamilies (Fig. 5b). The traditional phylogenetic hypothesis could be statistically ruled out based on the results of the Templeton (1983) test, but could not be ruled out based on the results of the Kishino-Hasegawa (1989) test. These discrepancies from the traditional phylogenies of copepod orders and calanoid superfamilies (Fig. 5a,b) (Park 1986; Huys and Boxshall 1991) suggest that such evolutionary relationships among copepods remain somewhat uncertain and warrant further examination; however, taxon sampling was limited and these results must be accepted with caution.

The strong level of phylogenetic resolution between copepod orders indicates that the rate of evolution of the D9/D10 region of the 28S rRNA gene is appropriate for resolving evolutionary relationships at this taxonomic level. It therefore seems appropriate to expand this $28 \mathrm{~S}$ analysis with representatives of additional copepod orders, as well as to examine these higher taxonomic relationships with additional molecular (e.g. protein coding genes) and morphological characters, since there remain many open questions in copepod systematics and evolution.
$16 \mathrm{~S}$ phylogenetic analysis of the Euchaetidae

In Park's (1995) most recent morphology-based revision of the family Euchaetidae, he distinguishes the genus Euchaeta from the genus Paraeuchaeta by two synapomorphic features: in the genus Euchaeta the appendicular caudal setae are straight and much thicker and longer than the distal marginal caudal setae in females, and the third exopodal segment of the male left fifth leg tapers into a long spine, with the exception of the independent species Euchaeta spinosa (Fig. 1a). Conversely, Paraeuchaeta species are characterized by geniculated or smoothly curved female appendicular caudal setae, which are thinner and not always longer than the distal marginal caudal setae, and a third exopodal segment of the male left fifth leg which terminates in a minute vestigial spine.

The classification of two genera, Euchaeta and $\mathrm{Pa}$ raeuchaeta, is supported by the results of the $16 \mathrm{~S}$ analysis, though not as most recently defined by Park (1995). There is a clear division between taxa of the marina species group (Euchaeta marina and E. rimana) and the Paraeuchaeta species ( $P$. norvegica, $P$. elongata, $P$. similis, and $P$. antarctica), but Euchaeta acuta is placed within the Paraeuchaeta clade with strong MP and NJ bootstrap support (86 and 96\%, respectively), suggesting that E. acuta may need to be reclassified within Paraeuchaeta (Fig. 6). The exclusion of E. acuta from the E. marina/E. rimana clade supports Bradford's (1974) argument that the genus Euchaeta should include only the four members of the marina species group (Euchaeta marina, Euchaeta rimana, Euchaeta marinella, and Euchaeta indica), and that the remaining species belong to the genus Paraeuchaeta, which may require further subdivision (Bradford et al. 1983). The evolutionary position of E. acuta with respect to the four Paraeuchaeta species remains uncertain, because although the majority of analyses favored E. acuta as the sister group to $P$. norvegica and $P$. elongata, this was with marginal bootstrap support.

It is also possible that the placement of Euchaeta acuta within the Paraeuchaeta clade is a consequence of incomplete taxon sampling. Some species groups were not represented in this study, such as the concinna species group, which is basal to the marina species group on Park's (1995) morphology-based tree (Fig. 1a). In support of this possibility, E. acuta was grouped with Euchaeta rimana and Euchaeta marina with moderately high MP bootstrap support (77\%) when Pseudocalanus newmani was the outgroup, and this possibility could not be statistically rejected based on the results of Templeton (1983) and Kishino-Hasegawa (1989) tests. Clearly, future studies should involve more complete taxon sampling and additional molecular data to draw firmer conclusions about the relationship between Euchaeta and Paraeuchaeta species. 
Phylogenetic mapping of morphological and ecological traits

Our phylogenetic mapping analysis suggested that straight female appendicular caudal setae which are thicker and longer than the distal marginal caudal setae, and a male fifth leg on which the third exopodal segment tapers into a long spine, each evolved independently twice within the family Euchaetidae (Fig. 7a and b). Thus, if the evolutionary position of Euchaeta acuta within the Paraeuchaeta clade is indeed accurate, each of these two morphological traits evolved convergently during the evolutionary history of this copepod family.

When vertical migration behavior was mapped onto the most parsimonious $16 \mathrm{~S}$ tree (i.e. Fig. 6), the resultant tree suggested that a deep-living, vertically migrating lifestyle typical of Paraeuchaeta species was lost twice independently within the Euchaetidae (Fig. 7c). Further, based on the character state reconstruction depicted in Fig. 7(c), the most recent common ancestor of the Euchaetidae and the Aetideidae was a deep-living, vertically migrating copepod, which is consistent with the fact that this lifestyle is widespread throughout the calanoid superfamily Clausocalanoidea, and more specifically the family Aetideidae (Matthews 1964; Park 1978; Bradford and Jillett 1980). Consequently, Fig. 7(c) suggests that a bathypelagic, vertically migrating lifestyle is an ancestral trait of the family Euchaetidae which has been lost apomorphically in Euchaeta. This common ancestor also lived in temperate waters (Fig. 8). The ancestor likely possessed Paraeuchaeta traits as a deep-living, vertically migrating copepod but instead of living in cold waters, it lived in temperate waters. When the species' distributions changed to polar waters, the possession of Paraeuchaeta morphological and behavioral traits might have allowed them to survive in cold waters.

Independent losses of a trait or set of traits is generally less likely from an evolutionary perspective than a single loss of a trait or traits, a possibility which can not be ruled out based on the result obtained when Pseudocalanus newmani was the outgroup and Euchaeta acuta grouped with Euchaeta marina and Euchaeta rimana. Consequently, these results should be approached with caution, and future investigations must include more species representing both Euchaeta and Paraeuchaeta in order to form stronger conclusions.

\section{Molecular clock, barriers to gene flow, and speciation}

Our investigation of the estimated time of divergence for the sibling species Euchaeta marina and Euchaeta rimana using a molecular clock approach suggested that these sister taxa diverged 2.6 to 3.4 million years ago. This sibling species pair is found on either side of the Panamanian Isthmus, which severed the connection between the Caribbean and the eastern Pacific 2.9 to 3.5 million years ago (Bermingham and Lessios 1993, and refer- ences therein); E. marina inhabits the Atlantic Ocean and E. rimana resides in the Pacific. Our results support a vicariant speciation event for E. marina and E. rimana, caused by the rise of the Panamanian land bridge. Thus, we propose that the sibling species E. marina and $E$. rimana be added to the existing list of transisthmian sister taxa.

Acknowledgements Many thanks are extended to all who generously supplied copepods for this project, including P. Caparroy, B. Frost, S. Kaartvedt, G. Kleppel, T. Snell, and D. Lonsdale. We also thank F. Ferrari for identifying several of the copepod species included in this study, and B. Cataletto for designing the primers. We thank three anonymous reviewers for their useful comments. This work was supported by the following grants: NSF Grant OCE-9314934 to J.Y., DEB-9615178, BSR-9119867, BSR-9107838 to A.M., and NYS Sea Grant R/CE-7 to D. Lonsdale.

\section{References}

Abele LG, Spears T, Kim W, Applegate M (1992) Phylogeny of selected maxillopodan and other crustacean taxa based on $18 \mathrm{~S}$ ribosomal nucleotide sequences: a preliminary analysis. Acta zool, Stockh 73: 373-382

Andranov VN (1991) On renaming of some taxa in Calanoida (Crustacea). Zool Zh 70: 133-135 (in Russian with English summary)

Bermingham E, Lessios HA (1993) Rate variation of protein and mitochondrial DNA evolution as revealed by sea urchins separated by the Isthmus of Panama. Proc natn Acad Sci USA 90: 2734-2738

Bradford JM (1973) Revision of family and some generic definitions in the Phaennidae and Scolecithricidae (Copepoda: Calanoida). NZ J1 mar Freshwat Res 7: 133-152

Bradford JM (1974) Euchaeta marina (Prestandrea) (Copepoda, Calanoida) and two closely related new species from the Pacific. Pacif Sci 28: 159-169

Bradford JM, Haakonssen L, Jillett JB (1983) The marine fauna of New Zealand: pelagic calanoid copepods: families Euchaetidae, Phaennidae, Scolecithricidae, Diaixidae, and Tharybidae. Bull NZ Dep scient ind Res 90: 1-150

Bradford JM, Jillett JB (1980) The marine fauna of New Zealand: pelagic calanoid copepods: family Aetideidae. Bull NZ Dep scient ind Res 86: 1-102

Brodsky KA (1950) Calanoida of the far eastern seas and polar basin of the USSR. In: Strelkov AA (ed) Keys to the fauna of the USSR. Vol. 35. Zoological Institute of the Academy of Sciences of the USSR, Moskva-Leningrad, pp 1-442 (in Russian)

Bucklin A, Frost BW, Kocher TD (1992) DNA sequence variation of the mitochondrial 16S rRNA in Calanus (Copepoda; Calanoida): intraspecific and interspecific patterns. Molec mar Biol Biotechnol 1: 397-407

Bucklin A, Frost BW, Kocher TD (1995) Molecular systematics of six Calanus and three Metridia species (Calanoida: Copepoda). Mar Biol 121: 655-664

Burton RS, Lee B (1994) Nuclear and mitochondrial gene genealogies and allozyme polymorphism across a major phylogeographic break in the copepod Tigriopus californicus. Proc natn Acad Sci USA 91: 5197-5201

Farris JS (1969) A successive approximations approach to character weighting. Syst Zool 18: 374-385

Felsenstein J (1981) Evolutionary tree from DNA sequences: a maximum likelihood approach. J molec Evolut 17: 368-376

Felsenstein J (1985) Confidence limits on phylogenies: an approach using the bootstrap. Evolution 39: 783-791

Felsenstein J (1989) PHYLIP-phylogeny inference package (Ver. 3.4). Cladistics 5: 164-166 
Ferrari F, Dojiri M (1987) The calanoid copepod Euchaeta antarctica from Southern Ocean Atlantic Sector midwater trawls, with observations on spermatophore dimorphism. J Crustacean Biol 7: 458-480

Fitch WM (1971) Toward defining the course of evolution: minimal change for a specific tree topology. Syst Biol 20: 406-416

Fontaine M (1967) Two new species of Euchaeta (Copepoda, Calanoida). Crustaceana 12: 193-213

Fontaine M (1988) Taxonomy and distribution of the antarctica species group of the genus Euchaeta (Copepoda, Calanoida). In: Kornicker LS (ed) Biology of the antarctic seas. XIX. Antarctic Res Ser 47: 27-57

Funk DJ, Futuyma DJ, Orti G, Meyer A (1995) Mitochondrial DNA sequences and multiple data sets: a phylogenetic study of phytophagous beetles (Chrysomelidae: Ophraella). Molec Biol Evolut 12: 627-640

Hasegawa M, Kishino H, Yano T (1985) Dating of the human-ape splitting by a molecular clock of mitochondrial DNA. J molec Evolut 22: 160-174

Huys R, Boxshall G (1991) Copepod evolution. The Ray Society, London

Jackson JBC, Jung P, Coates AG, Collins LS (1993) Diversity and extinction of tropical American mollusks and emergence of the Isthmus of Panama. Science 260: 1624-1625

Kimura MA (1980) A simple method for estimating evolutionary rate of base substitutions through comparative studies of nucleotide sequences. J molec Evolut 16: 111-120

Kishino H, Hasegawa M (1989) Evaluation of the maximum likelihood estimate of the evolutionary tree topologies from DNA sequence data, and the branching order in Hominoidea. J molec Evolut 29: 170-179

Knowlton N, Weigt LA, Solorzano LA, Mills EK, Bermingham E (1993) Divergence in proteins, mtDNA, and reproductive compatibility across the Isthmus of Panama. Science 260: 1629-1632

Maddison WP, Maddison DR (1992) MacClade: analysis of phylogeny and character evolution, Version 3.0. Sinauer Associates, Sunderland, Massachusetts

Matthews JBL (1964) On the biology of some bottom-living copepods (Aetideidae and Phaennidae) from western Norway. Sarsia 16: $1-46$

Palumbi SR, Benzie J (1991) Large mitochondrial DNA differences between morphologically similar penaeid shrimp. Molec mar Biol Biotechnol 1: 27-34

Palumbi SR, Martin A, Romano S, MacMillan W, Stice L, Grabowski G (1991) The simple fool's guide to PCR (Ver. 2). University of Hawaii Press, Honolulu

Park T (1975) Calanoid copepods of the family Euchaetidae from the Gulf of Mexico and western Caribbean Sea. Smithson Contr Zool 196: 1-26

Park T (1978) Calanoid copepods belonging to the families Aetideidae and Euchaetidae from antarctic and subantarctic waters. In: Pawson DL (ed) Biology of the antarctic seas. VII. Antarctic Res Ser 27: 91-290

Park T (1986) Phylogeny of calanoid copepods. Syllogeus (Nat Mus Can) 58: 191-196
Park T (1994) Geographic distribution of the bathypelagic genus Paraeuchaeta (Copepoda, Calanoida). In: Ferrari FD, Bradley BP (eds) Ecology and morphology of copepods. Vol. 292/293. Kluwer Academic Publishers, Dordrecht, The Netherlands, pp 317-332

Park T (1995) Taxonomy and distribution of the marine calanoid copepod family Euchaetidae. Bull Scripps Instn Oceanogr 29: $1-203$

Saiki RK, Gelfand DH, Stoffel S, Scharf S, Higuchi R, Horn GT, Mullis KB, Erlich HA (1988) Primer-directed enzymatic amplification of DNA with a thermostable DNA polymerase. Science 239: 487-491

Saitou N, Nei M (1987) The neighbor-joining method: a new method for reconstructing phylogenetic trees. Molec Biol Evolut 4: 406-525

Sambrook J, Fristch EF, Maniatis T (1989) Molecular cloning: a laboratory manual, 2nd edn. Cold Spring Harbor Laboratory, Cdd Spring Harbor, New York

Sars GO (1902) Copepoda Calanoida. An account of the Crustacea of Norway. Bergens Mus Arb 4: 29-144

Swofford DL (1997) PAUP*: phylogenetic analysis using parsimony (*and other methods), Version 4.0. Sinauer Associates, Sunderland, Massachusetts

Tautz D, Hancock JM, Webb DA, Tautz C, Dover GA (1988) Complete sequences of the rRNA genes of Drosophila melanogaster. Molec Biol Evolut 5: 366-376

Templeton AR (1983) Phylogenetic inference from restriction endonuclease site maps with particular reference to the humans and apes. Evolution 37: 221-244

Thompson JD, Higgins DG, Gibson TJ (1994) CLUSTAL W improving the sensitivity of progressive multiple sequence alignment through sequence weighting, position specific gap penalties and weight matrix choice. Nucleic Acids Res 22: 46734680

Towner P (1991) Purification of DNA. In: Brown TA (ed) Essential molecular biology. Vol. 1. Oxford University Press, Oxford, pp 47-68

Vervoort W (1957) Copepods from antarctic and sub-antarctic plankton samples. In: Johnston TH (ed) British, Australian, and New Zealand Antarctic Research Expedition, Ser. B. Vol. 3. BANZAR Expedition Committee, University of Adelaide, Australia, pp 1-160

Yen J (1983) Effects of prey concentration, prey size, predator life stage, predator starvation, and season on predation rates of the carnivorous copepod Euchaeta elongata. Mar Biol 75: 69-77

Zardoya R, Costas E, Lopez-Rodas V, Garrido-Pertierra A, Bautista JM (1995) Revised dinoflagellate phylogeny inferred from molecular analysis of large-subunit ribosomal RNA gene sequences. J molec Evolut 41: 637-645

Zmijewska MI, Yen J (1993) Seasonal and diel changes in the abundance and vertical distribution of the Antarctic copepod species Calanoides acutus, Calanus propinquus, Rhincalanus gigas, Metridia gerlachei, and Euchaeta antarctica (Calanoida) in Croker Passage (Antarctic Peninsula) Oceanologia 35: 101-127 